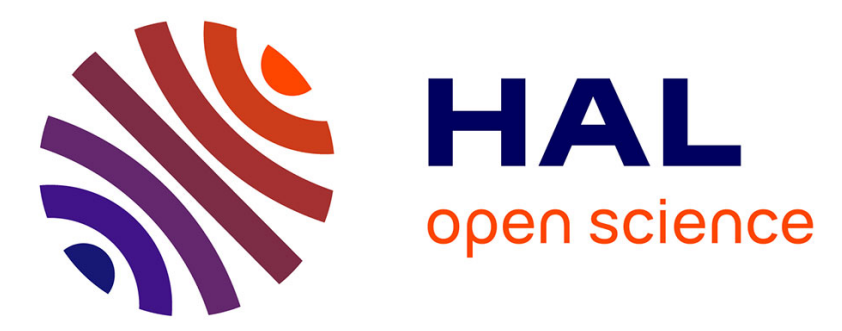

\title{
Modified SnO2-APTES gas sensor for selective ammonia detection at room temperature
}

\author{
Mohamad Hijazi, Mathilde Rieu, Valérie Stambouli, Guy Tournier, Jean-Paul \\ Viricelle, Christophe Pijolat
}

\section{- To cite this version:}

Mohamad Hijazi, Mathilde Rieu, Valérie Stambouli, Guy Tournier, Jean-Paul Viricelle, et al.. Modified SnO2-APTES gas sensor for selective ammonia detection at room temperature. SURFOCAP'17 - 3rd INTERNATIONAL WORKSHOP ON FUNCTIONALIZED SURFACES FOR SENSOR APPLICATIONS, UFC: Université de Franche-Comté; Institut FEMTO-ST: Franche-Comté électronique mécanique thermique et optique - Sciences et technologies, May 2017, Besançon, France. pp.319-322 / MATPR7087, 10.1016/j.matpr.2018.10.424 . hal-01920481

\section{HAL Id: hal-01920481 \\ https://hal.science/hal-01920481}

Submitted on 22 Nov 2018

HAL is a multi-disciplinary open access archive for the deposit and dissemination of scientific research documents, whether they are published or not. The documents may come from teaching and research institutions in France or abroad, or from public or private research centers.
L'archive ouverte pluridisciplinaire HAL, est destinée au dépôt et à la diffusion de documents scientifiques de niveau recherche, publiés ou non, émanant des établissements d'enseignement et de recherche français ou étrangers, des laboratoires publics ou privés. 


\title{
Modified $\mathrm{SnO}_{2}$-APTES gas sensor for selective ammonia detection at room temperature
}

\author{
Mohamad Hijazi ${ }^{\mathrm{a}}$, Mathilde Rieu ${ }^{\mathrm{a}^{*}}$, Valérie Stambouli ${ }^{\mathrm{b}}$, Guy Tournier ${ }^{\mathrm{a}}$, Jean-Paul \\ Viricelle $^{\mathrm{a}}$, Christophe Pijolat ${ }^{\mathrm{a}}$ \\ ${ }^{a}$ École Nationale Supérieure des Mines, SPIN-EMSE, CNRS:UMR5307, LGF, F-42023 Saint-Étienne, France \\ ${ }^{b}$ LMGP, Université Grenoble-Alpes, Grenoble INP-MINATEC, 3 parvis Louis Néel, CS 50257, 38016 Grenoble Cedex 1, France
}

\begin{abstract}
The feasibility of room temperature ammonia gas sensors based on tin dioxide $\left(\mathrm{SnO}_{2}\right)$ functionalization has been demonstrated. 3-aminopropyltriethoxysilane (APTES) was used as an intermediate step, followed by functionalization with molecules having acyl chloride with different end functional groups molecules such as alkyl, acid and ester groups. Modified films were characterized by attenuated total reflectance infra-red spectroscopy (ATR-FTIR). Upon exposure to ammonia gas, the electrical conductance of alkyl, acid and ester modified $\mathrm{SnO}_{2}$-APTES increases, whereas other reducing gases such as ethanol, carbon monoxide and acetone show no change in conductance. Furthermore, ester modified $\mathrm{SnO}_{2}$ is more selective than acid modified sensor regarding ethanol and carbon monoxide gases.
\end{abstract}

Keywords: $\mathrm{SnO}_{2}$; Screen printing; Molecularlly functionalization; APTES; Gas snensors; Ammonia gas; Selectivity; Room temperature detection

\section{Introduction}

The detection of ammonia gas is of great interest in many fields such as medical and environmental monitoring. Ammonia can be detected by different sensing materials like carbon nanotubes or polyaniline [1]. Metal oxide gas sensors are promising devices because they are small in size, easy to use and less expensive than other spectrometry techniques. Thick films of metal oxide can be produced by screen printing which is simple, reproducible and low cost technique. Tin dioxide material allows the detection of many gaseous compounds. Nevertheless, the $\mathrm{SnO}_{2}$-based sensors suffer from two major drawbacks which constitute an obstacle to their development. $\mathrm{SnO}_{2}$ has lack of selectivity because it has high affinity with many gases. In addition, $\mathrm{SnO}_{2}$ has high operating temperature between $250{ }^{\circ} \mathrm{C}$ and $500{ }^{\circ} \mathrm{C}$. Many approaches were described in the literature to cover these drawbacks e.g. $\mathrm{SnO}_{2} / \mathrm{carbon}$ nanotubes and $\mathrm{SnO}_{2} /$ polyaniline hybrid sensors. Another way is the surface molecular functionalization of $\mathrm{SnO}_{2}$ [2]. Functionalization on silicon nanowire field effect transistors has showed changes in the working principle of the sensors, while these sensors are still lack to selectivity. In this case, the interactions are between the gas and the grafted organic layer rather than the metal oxide substrate. These interactions lead to changes in the dipole moment that variate the electrical properties of substrate (e.g. Si) [3]. Molecular modified $\mathrm{SnO}_{2}$ sensors work at ambient temperature for selective ammonia detection is not reported in literature. This sensors has low power consumption, hence it can be used in smart portable devices.

\footnotetext{
* Corresponding author. Tel.: +33477420282.

E-mail address: Rieu@emse.fr
} 
In this work, we were intended to achieve surface functionalization of $\mathrm{SnO}_{2}$ thick film. The purpose of functionalization was to passivate the surface states on the $\mathrm{SnO}_{2}$ sensors by molecular layer aiming to optimize their interactions with ammonia gas. The first step of molecular modification was the attachment of APTES. The second step was to fix alkyl, acid and ester functional groups on APTES modified $\mathrm{SnO}_{2}$. These sensors were tested to ammonia gas at room temperature. The selectivity was examined versus ethanol, carbon monoxide and acetone gases.

\section{Experimental section}

In this study, $\mathrm{SnO}_{2}$ thick films are deposited on alumina substrate by screen-printing technique. A semi-automatic Aurel C890 machine was used. The procedures for preparing the $\mathrm{SnO}_{2}$ ink and sensor fabrication parameters have been described elsewhere [4]. The $\mathrm{SnO}_{2}$ ink is produced by mixing $\mathrm{SnO}_{2}$ powder (Prolabo Company) with a solvent and an organic binder. This ink was then screen printed on an alpha-alumina substrate $\left(38 \times 5 \times 0.4 \mathrm{~mm}^{3}\right)$ provided with sputtered gold electrodes. The deposited $\mathrm{SnO}_{2}$ material is finally annealed for $10 \mathrm{~h}$ at $700{ }^{\circ} \mathrm{C}$ in air to get $\mathrm{SnO}_{2}$ film with a thickness of 40 microns. The $\mathrm{SnO}_{2}$ particles sizes were found to be around $75 \mathrm{~nm}$.

The functionalization of $\mathrm{SnO}_{2}$ was carried out by two steps which lead to covalent attachment of alkyl, acid and ester end functional groups. The first step is the condensation reaction between the hydroxyl groups present on $\mathrm{SnO}_{2}$ surface and 3-aminopropyltriethoxysilane (APTES from ACROS Organics). This step generates a film terminated by amine groups $\left(\mathrm{SnO}_{2}\right.$-APTES) which will act as a substrate for the second step of modification. Silanization in liquid phase has been described elsewhere [5]. In a first step, $\mathrm{SnO}_{2}$ sensors were immersed in $50 \mathrm{mM}$ APTES dissolved in $95 \%$ absolute ethanol and $5 \%$ of deionized water for $5 \mathrm{~h}$ under stirring at room temperature. After reaction, the sensors were rinsed with absolute ethanol and dried under $\mathrm{N}_{2}$ flow. As a second step, these terminal amine groups of APTES allow the coupling reaction with molecules bearing acyl chloride group. In the second step, alkyl, acid and ester end group grafting was achieved by immersing APTES modified $\mathrm{SnO}_{2}$ in a solution of $10 \mathrm{mM}$ of hexanoyl chloride (98\%, ALDRICH, alkyl: $\left.\mathrm{C}_{6} \mathrm{H} 11 \mathrm{ClO}\right), 1,4$-butanedicarbonyl chloride (98\%, Fluka, acid: $\mathrm{C}_{6} \mathrm{H}_{8} \mathrm{Cl}_{2} \mathrm{O}_{2}$ ) or methyl adipoyl chloride $\left(96 \%\right.$, Alfa Aesar, ester: $\mathrm{C}_{7} \mathrm{H}_{11} \mathrm{ClO}_{3}$ ), with $5 \mu \mathrm{L}$ of triethylamine (Fluka) in 5 $\mathrm{mL}$ of chloroform as solvent for 12 hours under stirring. The sensors were then rinsed with chloroform and dried under $\mathrm{N}_{2}$ flow.

The obtained sensors were tested under gases in a test bench at $25{ }^{\circ} \mathrm{C}$ to check the effects of functionalization on sensor performance. In this test bench, sensor is installed in an $80 \mathrm{~cm}^{3}$ glass chamber under constant gas flow of 15 $1 / \mathrm{h}$. It is provided with gas mass flow controllers which allow controlling the concentrations of different gases. Sensors selectivity was tested versus ethanol, carbon monoxide and acetone gases.

\section{Results and discussion}

Regarding the characterization of the functionalized films by ATR-FTIR, the most important signals corresponding to APTES were found between 800 and $1800 \mathrm{~cm}^{-1}$ as shown in Fig. 1. The peak at $938 \mathrm{~cm}^{-1}$ is attributed to Sn-O-Si stretch [6]. The strong absorption peaks at 1029 and $1125 \mathrm{~cm}^{-1}$ are attributed to Si-O bond of polymerized APTES on the surface. $\mathrm{NH}_{3}{ }^{+}$(protonation of amine) and $\mathrm{NH}_{2}$ vibrational signals are found at $1486 \mathrm{~cm}^{-1}$ and $1570 \mathrm{~cm}^{-1}$ respectively. These peaks confirm the presence of APTES on $\mathrm{SnO}_{2}$ after silanization.

APTES film was used as a substrate for the second step of functionalization. The second step of sensors modification is the attachment of a film on $\mathrm{SnO}_{2}$-APTES, ended with alkyl, acid or ester groups.

Alkyl, acid and ester modified $\mathrm{SnO}_{2}$ (red, orange and green curves respectively) FTIR spectra presented in Fig. 1 exhibit two peaks at $1547 \mathrm{~cm}^{-1}$ and $1645 \mathrm{~cm}^{-1}$ which correspond to carbonyl stretch mode and $\mathrm{N}-\mathrm{H}$ bending mode of amide respectively. An additional broad peak between $\sim 3000$ and $\sim 3600 \mathrm{~cm}^{-1}$ corresponds to N-H stretch of amide. These peaks confirm the success of the reaction between amine group of APTES and acyl chloride group and the formation of amide bond. Asymmetrical C-H stretching mode of $\mathrm{CH}_{3}$ for $\mathrm{SnO}_{2}$-APTES-alkyl and for $\mathrm{SnO}_{2}$-APTESester appears at $2965 \mathrm{~cm}^{-1}$. The stretching peak of carbon double bounded to oxygen of ester group of $\mathrm{SnO}_{2}$-APTESester is found at $1734 \mathrm{~cm}^{-1}$ (Fig. 1, green curve).

Therefore, FTIR analysis confirms that functionalization is effectively achieved on $\mathrm{SnO}_{2}$-APTES after reaction with acyl chloride products by showing the presence of ester, acid and alkyl molecules. 


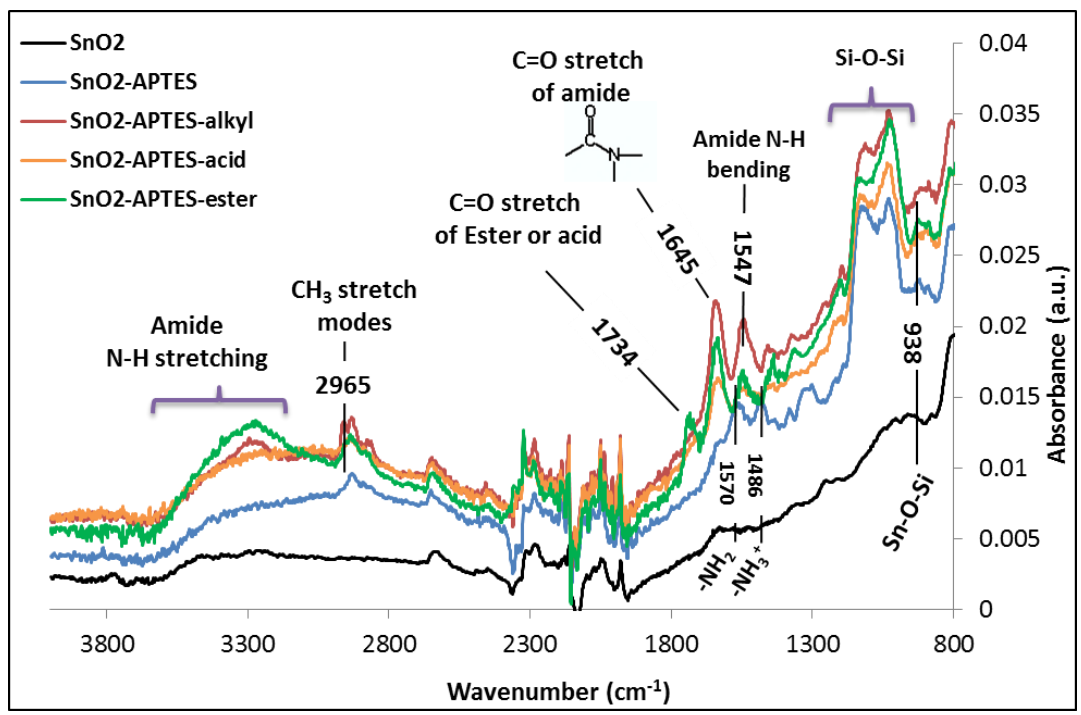

Fig. 1. ATR-FTIR spectra of $\mathrm{SnO}_{2}$ (black curve), $\mathrm{SnO}_{2}$-APTES (blue curve), $\mathrm{SnO}_{2}$-APTES-alkyl (red curve), $\mathrm{SnO}_{2}$-APTES-acid (orange curve), and $\mathrm{SnO}_{2}$-APTES-ester (green curve) films.

The first part of the test under gases was to show the characteristic of the response of different sensors to ammonia gas. As shown in Fig. 2, the sensors were tested to $100 \mathrm{ppm}$ of ammonia balanced with 5\% RH air at 25 ${ }^{\circ} \mathrm{C}$. Figure 2 (red curve) shows that the conductance of pure $\mathrm{SnO}_{2}$ decreases upon exposure to ammonia gas. This type of response has been founded before by Kamalpreet Khun Khun et al. [7] at temperature between 25 to $200{ }^{\circ} \mathrm{C}$.

APTES modified $\mathrm{SnO}_{2}$ sensor present no change in conductance upon exposure to $100 \mathrm{ppm}$ of ammonia (Fig. 2, dark green curve). This behavior indicates that the $\mathrm{SnO}_{2}$ surface is well covered by APTES molecules because the negative response observed on pure $\mathrm{SnO}_{2}$ is totally inhibited.

$\mathrm{SnO}_{2}$-APTES-alkyl, $\mathrm{SnO}_{2}$-APTES-acid and $\mathrm{SnO}_{2}$-APTES-ester exhibit increase in conductance upon exposure to $100 \mathrm{ppm}$ of ammonia gas as presented in Fig. 2. In addition, the response of $\mathrm{SnO}_{2}$-APTES-ester and $\mathrm{SnO}_{2}$-APTESacid are more important than of $\mathrm{SnO}_{2}$-APTES-alkyl. These responses could be related to the different polarities of the attached end functional groups. Ester and acid are electron withdrawing groups, while alkyl is mostly considered as nonpolar. Ammonia molecule is a nucleophilic molecule (donating). Regarding the interaction between ester and acid from one side and ammonia from the other side, dipole-dipole interaction is taking place. In the contrary, in the case of $\mathrm{SnO}_{2}$-APTES-alkyl, the interaction is of induced dipole type because ammonia is a polar molecule and alkyl end group is mostly nonpolar. These two interactions (i.e. dipole-dipole and induced-dipole) result in a modification in the dipole moment which changes the conductance of $\mathrm{SnO}_{2}$. It was reported by B. Wang et al. [3], that the dipoledipole interaction is always stronger than induced dipole interaction. That is why the response of ester and acid modified sensors is more significant than alkyl one.

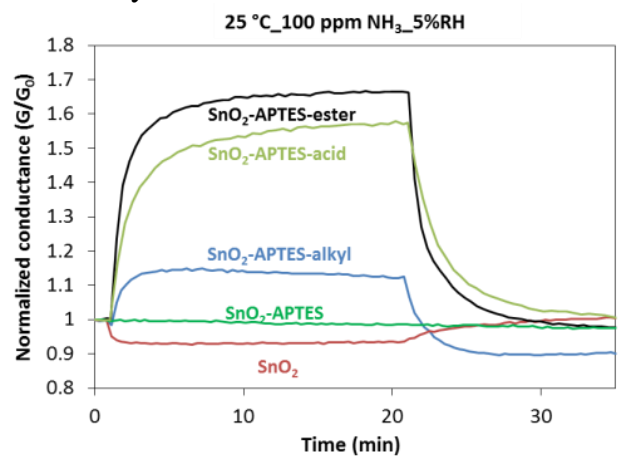


Fig. 2. The sensor response of $\mathrm{SnO}_{2}\left(\mathrm{G}_{0}=1.4 \times 10^{-5} \Omega^{-1}\right)$, $\mathrm{SnO}_{2}$-APTES $\left(\mathrm{G}_{0}=7.9 \times 10^{-6} \Omega^{-1}\right), \mathrm{SnO}_{2}$-APTES-alkyl $\left(\mathrm{G}_{0}=1.5 \times 10^{-5} \Omega^{-1}\right)$, and $\mathrm{SnO}_{2}-$ APTES-ester $\left(\mathrm{G}_{0}=9.5 \times 10^{-6} \Omega^{-1}\right)$ to $100 \mathrm{ppm}$ ammonia gas balanced with humid air $(5 \% \mathrm{RH})$ at $25^{\circ} \mathrm{C}$.

Figure 3 shows that the $\mathrm{SnO}_{2}$-APTES-ester sensor has almost no change in conductance upon exposure to 50 ppm of ethanol, carbon monoxide and acetone at $25{ }^{\circ} \mathrm{C}$. This means that ester modified sensor is selective to ammonia, at least in regards of the three tested gases. $\mathrm{SnO}_{2}$-APTES-acid is less selective to ammonia than $\mathrm{SnO}_{2}$ APTES-ester with respect to ethanol and carbon monoxide. $\mathrm{SnO}_{2}$-APTES-acid gives response to ethanol and carbon monoxide which are 1.05 and 1.04 respectively. $\mathrm{SnO}_{2}$-APTES-acid shows no response to acetone gas.

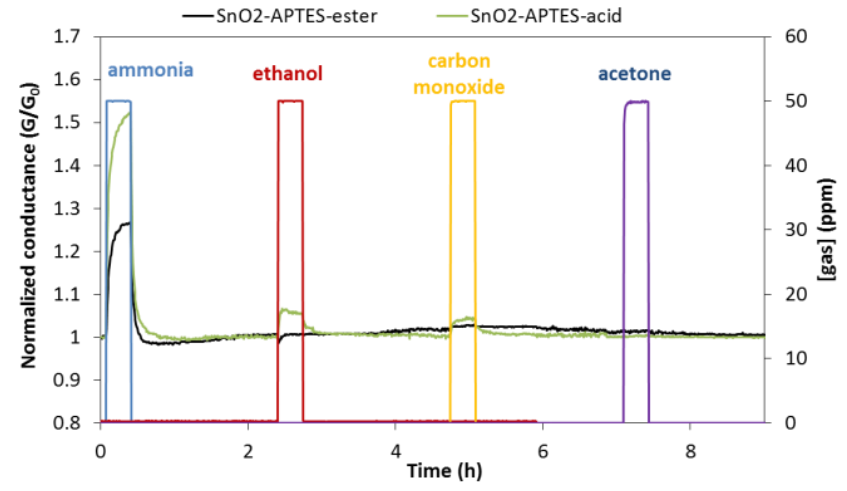

Fig. 3. The sensor response of $\mathrm{SnO}_{2}$-APTES-ester and $\mathrm{SnO}_{2}$-APTES-acid upon exposure to $50 \mathrm{ppm}$ of ammonia, ethanol, and acetone gases in air $(5 \% \mathrm{RH})$ at $25^{\circ} \mathrm{C}$.

\section{Conclusion}

Molecularly modified $\mathrm{SnO}_{2}$ thick films were produced by screen printing and solution chemical processes. The functionalized sensors by APTES were used as an amine terminated substrate for modification by alkyl, acid and ester functional groups. Alkyl, acid and ester modified $\mathrm{SnO}_{2}$-APTES sensors show response to ammonia in the opposite sense with respect to $\mathrm{SnO}_{2}$. Ester modified sensor is selective to ammonia gas at room temperature with respect to reducing gases like ethanol, carbon monoxide and acetone. The sensitivity of this sensor in real condition with high humidity level, as well as the detection mechanism will be more deeply investigated in the future work.

\section{References}

[1] L. Kumar, I. Rawal, A. Kaur, S. Annapoorni, Sens. Actuators B Chem. 240 (2017) 408-416.

[2] C.R.K. Rao, M. Vijayan, S. Anwar, D. Jeyakumar, J. Appl. Polym. Sci. (2011) 4819-4826.

[3] B. Wang, H. Haick, ACS Appl. Mater. Interfaces 5 (2013) 2289-2299.

[4] G. Tournier, C. Pijolat, Sens. Actuators B Chem. 106 (2005) 553-562.

[5] M. Le, C. Jimenez, E. Chainet, V. Stambouli, Sensors 15 (2015) 10686-10704.

[6] I. Matsubara, K. Hosono, N. Murayama, W. Shin, N. Izu, Sens. Actuators B Chem. 108 (2005) 143-147.

[7] K. Khun Khun, A. Mahajan, R.K. Bedi, J. Appl. Phys. 106 (2009) 124509. 